\title{
ENTREVISTA
}

\section{Dr. Ramiro Molina \\ El creador del concepto de sexualidad adolescente en Chile}

\author{
CECILIA VALENZUELA ${ }^{(1)}$
}

\author{
Este especialista ha dedicado su vida a mejorar la calidad \\ de vida de los jóvenes y a compartir conocimientos y avances \\ con todo el continente.
}



Durante el último año, figuró en los medios de comunicación como el más acérrimo defensor del derecho de los jóvenes -de todos, en realidada acceder a la píldora de emergencia o "del día después". Esto, pues fue nominado por la Universidad de Chile como experto ante la solicitud de asesoría del Tribunal Constitucional, la comisión de Salud de la Cámara de Diputados y el Senado. Hombre de "cuero duro", participó en paneles, foros y conferencias con científicos y políticos cuyos argumentos estaban en la vereda opuesta, pero nunca pareció molestarle. Con una retórica de aplastante lógica retrucó las ideologías con papers y sólida evidencia científica.

Siempre ha sido así. El doctor Ramiro Molina, profesor titular de la Casa de Bello, académico y fundador del Centro de Medicina Reproductiva y Desarrollo Integral del Adolescente, Cemera, nunca ha estado entre los que se quedan callados ante lo que considera aberrante o injusto $\mathrm{y}$, mejor aún, nunca ha aceptado estancamientos ni se ha conformado con lo que hay. Por esta larga trayectoria de luchas y aportes, recientemente la Sociedad Chilena de Obstetricia y Ginecología lo distinguió con el título de Maestro de la especialidad.

"Y maestro es quien ha formado una escuela", reflexiona el doctor Molina. Así, al mirar hacia atrás para relevar lo que entiende como sus mayores aportes, "aquellos donde hubo creación, creatividad", recuerda el traslado de lo que era la antigua maternidad del Hospital José Joaquín Aguirre -ubicada en lo que es el actual Instituto de Oncología- a sus actuales dependencias en el sector A del recinto asistencial, en enero de 1983, cuando era director del Departamento de Obstetricia y Ginecología. "Fue la maternidad privada más antigua del país y, durante muchos años, la más importante. Para hacer ese traslado hubo que mover al hospital completo para desocupar el sector A y reacondicionarlo, reconstruyendo pabellones y estructuras en 3.000 metros cuadrados", relata.

Eso significó un enorme trabajo y una gran inversión económica, con anécdotas entretenidas: en el subterráneo de la antigua maternidad prácticamente hubo que instalar una maestranza, porque había que adaptar catres y cunas; estas últimas habían sido traídas desde Francia por el doctor Carlos Monckeberg en 1925 y "eran

(1) Facultad de Medicina, Universidad de Chile. Independencia 1027. Santiago. Chile. cevalenzu@med.uchile.cl. 
muy grandes y pesadas, pero mejores que las modernas de la época, así que se acondicionaron y todavía están en funcionamiento. Además, recuerdo que negocié la maternidad con el ministro de Salud de la época: Büchi Buc".

\section{"NO VOY A DEJAR DE MOLESTAR"}

Pero, sin duda, su mayor aporte es la creación del concepto de salud sexual y reproductiva del adolescente en Chile. "Eso, a principios de los '80, era hablar en un lenguaje totalmente diferente. Fue muy interesante y desafiante, porque crear el Cemera significó desde generar la construcción de nuevas ideas hasta formar una nueva especialidad, con un programa absolutamente diferente a lo que había en materia pediátrica, pero apegado a nuestra realidad nacional, relacionado a la fecundidad adolescente", explica el doctor Molina.

Hoy, reconoce con orgullo, esta materia es parte de la enseñanza tanto de las ciencias biológicas como de las ciencias sociales, y es tema político nacional e internacional. "A Chile $y$ al Cemera se les ha dado un reconocimiento tan importante como es tener la presidencia mundial de la especialidad. Este modelo ya se ha copiado en otras universidades; vengo llegando de la Universidad de Antioquia, en cuya Facultad de Medicina se creó el centro NACER en el año 2003, con una tremenda inversión del gobierno, integrado a su Ministerio de Salud y a sus municipalidades para el trabajo directo con la población". Pero más contento lo tiene el que, para enero de 2010, se espera la apertura en nuestro país de los primeros 52 consultorios para adolescentes, replicando el modelo de atención creado en su centro, los cuales deberían seguir expandiéndose hasta llegar a 250.
Y, en la misma línea, considera que uno de sus más importantes legados fue la creación de un establecimiento educacional especializado para la atención de madres adolescentes, sus hijos y sus parejas. "El liceo Unopec, Unidad Operativa de Educación y Capacitación, nació durante el decanato del doctor Eduardo Rosselot, contando con todo su apoyo y el de las autoridades posteriores, pese a que fue tremendamente polémico en la época. Hoy se llama "Santa María de Conchalí", pertenece a esa municipalidad y el modelo es replicado en otras de estas instancias, aplicándose también en programas especializados del Sename y la Junaeb. Y, durante el gobierno de Ricardo Lagos, se entregó como un regalo a los príncipes de Asturias, cuando vinieron de visita al país".

En esta larga trayectoria, se destacan las asesorías que ha realizado en todo el continente en materia de planificación familiar, mandatado por las Naciones Unidas y, finalmente, la formación de decenas de especialistas, con los cuales se ha generado una masa crítica para continuar enfrentando los desafíos propios de lo que significa la sexualidad adolescente en nuestro país.

Hoy, lo que viene para el doctor Ramiro Molina es, según sus propias palabras, "tener la oportunidad de poner esta experiencia acumulada por tantos años a disposición del sector público ministerial, mediante un involucramiento en servicios hospitalarios importantes de Santiago; me gustaría intentarlo". Pero continuar siempre ligado a la Universidad de Chile, como docente e integrando la Comisión Superior de Evaluación Académica de la corporación; "porque no se me olvida cuál es mi casa", finaliza. 